Please reference this paper as

Kostakos, V. and O'Neill, E. (2004) Pervasive Computing in Emergency

Situations, Proceedings of the Thirty-Seventh Annual Hawaii

International Conference on System Sciences (CD/ROM), January 5-8,

2004, Computer Society Press, 2004.

\title{
Pervasive Computing in Emergency Situations
}

\author{
Vassilis Kostakos \& Eamonn O’Neill \\ Department of Computer Science, University of Bath \\ \{vk,eamonn\}@cs.bath.ac.uk
}

\begin{abstract}
Pervasive computing is still in its infancy and is mainly used in tightly constrained situations and environments. Examples such as "smart houses" are constrained both physically and conceptually. As a result, their computing power is not genuinely pervasive. This paper looks at how we can introduce pervasive systems in everyday large-scale public environments that are not tightly controlled or monitored. The impact of social issues on pervasive computing is discussed, along with ideas on overcoming the challenges posed by social requirements and constraints.
\end{abstract}

\section{Introduction}

Pervasive computing is a relatively new area of interest within Computer Science. Most challenges that have been faced so far in our attempts at designing pervasive systems have been technical, as the focus of much of the research has been on implementation aspects, such as the enabling technologies and techniques for combining and integrating various technologies in a system [13]. Although such issues are of great importance - after all, without the enabling technologies our hands are really tied - they do not address a vitally important issue of truly pervasive computing: integration and interaction with society. We argue that this is in large part due to the physical and conceptual limitations of current attempts at implementing pervasive systems.

Research to date in pervasive computing systems has focused primarily on small-scale, geographically constrained systems and the technical challenges that they entail. In this paper, we argue that for the vision of truly pervasive systems to be realized, we must develop better understandings of and design methodologies for large-scale pervasive systems and the societal challenges that they will entail. Rather than moving towards large-scale pervasive systems in a bottom-up way from today's small-scale systems, associated challenges and ad hoc solutions, we argue for following a top-down approach, drawing on the
HCI lessons that have already been learned in the development of more traditional computer systems. We revisit and extend the established HCI design foci of user, task and domain so that they are more relevant to designing for a social setting, proposing three analogous foci of citizen, sphere, and space.

We also describe how truly pervasive systems can be designed. Such systems will be used in a diverse range of everyday situations, including emergency situations. To do this, we first explain why pervasive systems in their current form are unsuitable and constrained, and then we describe how such systems should be designed, based on insights we have gained by examining emergency situations. We then elaborate on our decision to base the design of such systems on the public services model, and expand on this issue.

\section{Today's systems}

Pervasive computing was supposed to be part of our everyday life, and promised to assist us in all our activities and situations (such as emergencies) regardless of our location [33]. This vision of pervasive computing is that, ultimately, our whole society will benefit from such systems, and not just a few people doing very constrained tasks within physical "islands" of computing support. A pervasive system - highly embedded systems with fixed location [20] - cannot reach its full potential and cannot really be described as pervasive when it is limited to, say, a "smart house" or a "smart car". If the whole of society is to benefit from such systems, then the whole of society must be part of such a system.

A number of pervasive systems have been developed to date, and most have been designed for, and deployed in, specific physical locations and social situations [11] such as smart homes and living rooms, cars, labs, and business offices. This has led to a number of technological developments, such as tracking via sensing equipment and ultra sound [13], or even motion and object tracking using cameras [3]. Furthermore, various input and output technologies have been developed including speech, gesture [18], tactile feedback, and kinaesthetic input [24]. Additionally, environmental parameters have been 
used with the help of environmental sensors, and toolkits have been developed toward this end [5]. Another strand of research has focused on historical data analysis, which is not directly related to pervasive systems but has found practical applications in this area. Finally, many attempts have been made to provide an interface to these systems using tangible interfaces, or a metaphoric relation between atoms and bits [14].

Some projects have incorporated a wide range of such technologies into one system. Examples of such projects include Microsoft's EasyLiving [3], the Portolano project [6], and Cooltown by HP [17].

Finally, there have been attempts to provide a broader framework for dealing with all the pervasive technologies that have been developed so far. Rodden and Benford [25] provide a framework based on the six levels of buildings' lives. They classify current technologies according to which of the six levels they address. Rodden and Benford conclude that technologies are currently focusing only on the interior of buildings, with the danger of ignoring the broader settings.

\subsection{Overcoming the limitations of today's pervasive systems}

Most pervasive systems currently being implemented incorporate many of their envisioned characteristics. As we saw, however, not many address the true pervasive nature and potential of such systems - their ability to integrate into a very wide range of aspects of our everyday lives.

There are many dimensions, besides physical location, that would allow us better to understand pervasive systems, and enable us to design them. None of these dimensions has been explored fully, and there is a lot of research still to be done in these areas. One such area, which would certainly assist us in designing pervasive systems, is context awareness. There is no standard definition of context, and people seem to define it according to their needs. Because of its broad range of definitions, the notion of context is being explored by a number of research communities.

Context aware applications range from active badge call-forwarding [32] or the GroupWear nametags [2] to the simple example of the light that turns on when the refrigerator door opens. Today's context-aware systems use two main sources for providing contextual information: physical sensing and often simplistic assumptions. Physical sensing involves all of the aforementioned technologies that enable a system to track objects, humans, temperature, speed, time, etc. The assumptions are usually of the form if...then, such as "if there are more than 10 people in a room, then they are in a meeting”. We argue that a useful next step forward would be to replace the combination of physical sensing and crude assumptions with a combination of physical sensing and theoreticallyinformed, empirically-derived models. In this case, the system would not have to rely on crude assumptions but would use more complex, and hopefully accurate, models of interacting social contexts, which would allow the system to make a more "educated" guess at what is happening.

Another avenue for further exploration is the modeling of goals and intentions, both of the user and the system. There have been many attempts at providing methods for developing these or similar models, e.g. [9][15][29]. Existing work in this area needs to be explored and extended, and new areas developed, to provide effective means of taking account of users' goals and intentions in context-aware systems. This would, amongst other benefits, address the issue of having a pervasive system perform actions without the knowledge - or even consent - of users. In our vision of a truly pervasive computing environment, there is a danger that users could feel lost, wondering about the actions of the system or about the results of their own actions. This could be ameliorated by providing information to the users so that they are aware of the system's goals and intentions. A way of doing this that we are currently exploring involves a system that informs the users of its current status, the actions it is performing and its ultimate goals.

Another area of great interest with regard to pervasive systems is the social issues that the design, deployment and use of pervasive systems raise. As already mentioned, these issues form an integral part of the challenges that pervasive systems will face. It is inevitable that if pervasive systems are going to be part of our everyday lives, then pervasive systems will also be part of society. The next section takes a step in this direction by describing our vision of truly pervasive systems, and some of the challenges that we think we will have to face.

\section{Public and domestic pervasive systems}

A distinction that we would like to make is between public and domestic pervasive systems. This distinction reflects the common use of current pervasive systems in highly constrained domains such as the home, or by specific groups of people, while truly pervasive systems could potentially be made publicly available for general use. A public pervasive system could be a system that is not owned, and therefore controlled, by any specific person. Anyone would be allowed to make use of it, without regard for the physical location or identity of the user. 
Table 1. Characteristics of public and domestic pervasive systems.

\begin{tabular}{lll}
\hline & $\begin{array}{l}\text { Public Pervasive } \\
\text { Systems }\end{array}$ & $\begin{array}{l}\text { Domestic Pervasive } \\
\text { Systems }\end{array}$ \\
\hline Ownership & $\begin{array}{l}\text { Owned by national } \\
\text { governments, local } \\
\text { councils etc. Can be } \\
\text { used by anyone who is } \\
\text { a member of the }\end{array}$ & $\begin{array}{l}\text { Private or corporate } \\
\text { ownership. For use by } \\
\text { members of the family, } \\
\text { company, } \\
\text { organization, } \\
\text { Coverage }\end{array}$ \\
& $\begin{array}{l}\text { Large-scale. Public } \\
\text { areas such as squares } \\
\text { and parks; social units } \\
\text { such as towns, cities } \\
\text { and countries. }\end{array}$ & $\begin{array}{l}\text { Small-scale. Specific } \\
\text { locations such as a } \\
\text { house, company } \\
\text { headquarters, building } \\
\text { complex. }\end{array}$ \\
& Flexible & Optimized for specific \\
& & purposes \\
\hline
\end{tabular}

Making use of a pervasive system implies that one is physically present within the boundaries of the system. We can therefore assume that public pervasive systems would have to be large-scale (in terms of physical area coverage) while domestic ones are probably small-scale. There is no straightforward way of measuring how large the coverage area of a public system should be. However, given the aspiration that "everyone" should have access to it, our measuring units become social units: towns, cities, and countries. Therefore, a public system for a country would have to give access to everyone who is present within the boundaries of the country.

Of course, we can imagine public pervasive systems that have minimal area coverage. However, this hardly meets the defining goals of a public pervasive system to serve a wide community. On the other hand, domestic pervasive systems could have very wide area coverage. However, this would entail extensive costs for covering a large area, and would in many cases be uneconomical.

The following section attempts to provide a topdown generalized approach at designing public pervasive systems, as summarized in Table 1, by following traditional design methodologies that have been revisited to reflect the needs and requirements of designing a pervasive system for public use.

\section{Designing pervasive systems for the public}

The process of designing pervasive systems for the public is in many respects similar to designing traditional systems. In section 4, we discuss the applicability of established design approaches to pervasive systems for public use. Specifically, we address the established HCI wisdom of paying attention to user, task and domain in design and development work. Having surveyed these issues in section 4, we will discuss in section 5 how the ideas and models presented in section 4 interact with each other, and how they may be combined and used together in designing pervasive systems.

\subsection{Supporting users}

Truly pervasive computing systems will be so wide-scale, commonly used, yet transparent that they may usefully be viewed as public services, in the sense that we currently view public services such as electricity or transport provision. Thus, the intended users of these pervasive systems may usefully be viewed as "the public" of the societies in which these systems will be embedded. Following the traditional HCI edict of "know thy user" and attempting to define the characteristics of this public leads us to an examination of the concept of citizenship.

Designing a highly usable system is difficult, even if we know the specific users, tasks and domains that the system will support. The problem becomes much more difficult if the specific users are not known in advance, such as when we are designing a system for the public. Designing a system without studying its users is anathema to many in the HCI community, yet many systems are used by the public, and thus were designed without knowing in advance the specific users. Such systems include the subway, trains, buses, electricity, highway management (signs, lights, etc), telephone and television, and any system that supports or imposes social rules and regulations, such as voting [1]. These systems were designed without having specific users in mind, but by targeting citizens. So if we are to follow established HCI design wisdom in designing pervasive systems for the public, then we need to study our potential users: citizens.

Perhaps the most influential work to date on the meaning of citizenship has been T.H. Marshall's essay Citizenship and Social Class [21]. Marshall identifies three dimensions to citizenship, based on major historical transitions: the civil dimension, the political dimension and the social dimension. Marshall described these dimensions as follows:

"The civil element is composed of the rights necessary for individual freedom - liberty of the person, freedom of speech, thought and faith, the right to own property, and to conclude valid contracts, and the right to justice.

"By the political element I mean the right to participate in the exercise of political power, as a member of a body invested with political authority or as an elector of the members of such a body.

"By the social element I mean the whole range from the right to a modicum of economic welfare and security to the right to share to the full in the social heritage and to live the life of a civilized 
being according to the standards prevailing in society.” (pp. 10-11)

Although there have been arguments on specific details of Marshall's definition, the core meaning of citizenship is well described by the above three elements. Moreover, if this is how a citizen is defined, then this is how our users are described. If we are to create truly pervasive systems for our users, we ought to design our system in such a way that none of the above rights is violated. Indeed, we should design our systems in such a way that the systems maintain and support these rights.

\subsection{Supporting tasks}

In our design work, how can we possibly account for any arbitrary task that any particular user may wish to carry out using a public pervasive system? Our approach is to group tasks into categories, solely based on the nature of information with which they interact. Drawing on concepts from sociology and social policy, we have identified the public sphere, social sphere, and private sphere as three general categorizations of the types of tasks that citizens might be involved in and, hence, for which they might benefit from pervasive computing services.

The term public sphere was introduced by the German philosopher and sociologist Jürgen Habermas [10], who is linked to the Frankfurt School of social thought. The public sphere is a conceptual area of public debate in which issues of general concern can be discussed and opinions formed. It has also been defined as the space in which citizens deliberate about their common affairs, and a site where social meanings are generated, circulated, contested and reconstructed [7]. The public sphere, according to Habermas, was first developed in the salons and coffee houses of London, Paris, and other European cities. People would meet in such salons to discuss issues of the moment, using as their primary means for such debate the news sheets and newspapers which had just started to emerge in that period. Of particular importance was political debate, and although only small numbers of the population were involved, such salons were vital to the early development of democracy. The public sphere, in principle, involves individuals coming together as equals in a forum for public debate. Nevertheless, apart from pure debate, we could say that the public sphere involves individuals coming together as equals to exchange information.

Intimacy and familial relations - i.e. the "nonpublic sphere" - fall in two separate categories. The first category is the private sphere, which deals with completely private issues and information whose owners would not want them to be accessed by others at any point. The second category is the social sphere, also known as the social realm. The emergence of the social realm, which is neither private nor public, is a relatively new phenomenon. In recent generations, the telephone has been the technology most associated with the development and maintenance of a social sphere. It is argued that for some people the phone is a way of extending private boundaries beyond their home to family and friends who are welcome to call any time. The phone is used to capture a friend or household and bring them into an elastic, psychological domain of social space. A private call has the effect of relocating the other psychologically within the social sphere.

These different categories of social activities and information, i.e. the public, social and private spheres, describe how the information that we deal with can be categorized in social terms. These categories, along with their respective chunks of information, can help us in understanding how we can categorise a specific task, or a specific service offered by a public pervasive system. We can say that, for instance, the task of sending a message to a friend and the corresponding digital service that allows us to do so, fall in the category of the social sphere. On the other hand, a task like looking up the train timetables would be included in the public sphere. This "assignment" of services to specific spheres can help us in the design process, as we will describe later.

\subsection{Supporting domains}

The third crucial focus of established HCI design approaches is that of the domain. In current mobile and pervasive systems, the central role of the domain has often been usurped by the simpler concept of location [13][32]. As we have already described, the notion of location lacks many important qualities that are required to describe a domain. Some attempts at creating context-aware applications do go a long way in recognizing that it is not enough simply to know the physical location of a user [5]. A context-aware application that could provide the right information at the right time would be a big improvement in supporting the domain of the user and the task.

In trying to identify the social dimension of the notion of domain, we can start by describing the difference between space (physical location) and place (social dimensions) [11]. A place has embedded understandings and protocols of what is regarded as appropriate behavior. Places have values attached to them. Places tend to convey cultural meaning and frame our behavior. In addition, the presence of others within a place has an effect on how we behave and perceive the place. 
In defining a categorization strategy, we have again opted for a top-down approach, an approach which categorizes all possible places in three main groups: public spaces, social spaces and private spaces. Note that the terms public and private spaces are borrowed from sociology [8]. Confusingly, although they are called spaces, they are really places, in the sense used in [11]. The notions of public and private spaces carry with them a great number of characteristics and understandings, which are all peculiar to each society or social group. Public spaces are places that belong to the community, i.e. a square is a publicly owned space and thus is a public space. In such places, for example, you would have the police, not private security. They are places where you can sit down and chat with a friend without having to buy something, in contrast for example to a privately owned café. On the other hand, private spaces are places owned by someone, which can be used in whatever way the owner sees fit. Private spaces promote a sense of security and privacy. Public and private spaces are recognized by constitution precisely because of the importance that people attach to them - the physical locations as well as the notions, trends, rights, and common issues (i.e. the ingredients) that pervade these locations.

Social spaces are those spaces that are neither private nor public. Such spaces are usually offices, homes, shops and cars. In these spaces, people do have complete privacy, yet the space provides a greater sense of security and comfort compared to a public space.

The notion of public spaces is of great importance to architecture and civil engineering. In fact, a number of guidelines have been developed that describe what makes a good public space, and how they should be designed and built [23]. It has been found that successful public spaces are accessible, they cause people to engage in activities in them, they are comfortable, and finally they are sociable locations. These findings support our earlier point that a public

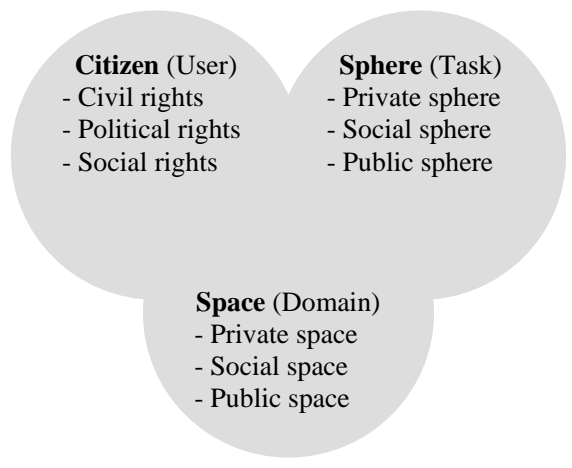

Figure 1. The three elements of designing pervasive systems for use by the public. (or social or private) space is much more than a physical location. There is a wealth of activities, social interactions and social understandings present. A pervasive system available in a public, social or private space should promote all of these characteristics in order to function in harmony with the space itself.

This section has outlined how established HCI design foci may be applied in the design of a public pervasive system. The concepts of user, task and domain were examined and extended so that they could be more appropriate for a social setting. The result of this process was the identification of three analogous concepts: citizen, sphere, and space, shown in Figure 1. These concepts can now serve as a basis for developing a pervasive system for public use.

\section{Emergency situations}

We now turn our attention to emergency situations and their over-arching characteristics. Our goal is to identify the characteristics of emergency situations, and identify the design requirements for any tools and services that people would like to use during an emergency.

An emergency situation is generally characterized by its impact on peoples' physical and psychological well-being, the severe implications of peoples' actions, and the need for timely responses. These characteristics imply that a service or tool that assists people during emergency situations should be easy for the person to use, should not require much thinking or complicated actions, and should be easily and readily accessible.

People who are trained to deal with emergency situations typically undergo rigorous and repetitious training. Tasks are turned into procedures that are executed enough times so that the trainees can perform them essentially without thinking. This way, the complexity of the actions is greatly reduced and proceduralized [16], much like our ability to drive and have a conversation simultaneously.

Ordinary people, however, who have not received training on how to deal with emergencies, can still deal with such situations. A tool and service that is used often in emergencies is the phone. The phone is used either to call for help, or to call someone who has been affected by the emergency. Despite the pressure and stress, people still use the phone network because it is perceived to be easy to use, without much thinking. As such, the phone service is a service that pervades the social and cognitive environments. Since it is used in the most extreme of situations, the phone service must be so easy to use that people can do so without much thinking. This, we argue, is a result of the way the phone service is being provided: as a public service. 


\subsection{Understanding public services}

The concept of a public service varies from country to country and from organization to organization. There are at least three different approaches to defining the meaning of a public service [18]:

- Services considered as public or for the common good. Such services are health, education and transportation. This view focuses on what is supplied.

- A service provided to the general public. This is often understood as the notion of a "universal service obligation", i.e. the obligation to supply the service universally at affordable terms, without distinguishing between the costs of supply in different regions. Thus, this view focuses on to whom and under which conditions the service is supplied. It should be noted that most services from the first category are often attributed with a universal service obligation.

- A service provided by a public entity, such as the government, a governmental agency, or a public enterprise. This view focuses on who supplies the service.

For the past 30 years, there have been numerous attempts to introduce measures to increase devolution and participation in public services [30]. Despite the frequent use of these terms, explicit definitions are hard to find.

- Definitions of participation range widely. For instance, the UN Development Program requires users to have "constant access to decision-making and power". Other views are wider, only requiring participants' views to be requested in order to "consider them before a decision is made" [30].

- Defining devolution can be problematic because of the debate on what is being devolved: power, responsibility, legitimacy, resources. Decentralization and devolution have been used interchangeably. Yet, some authors believe that decentralization refers to power shifts within a single organization, while devolution requires power shifts to autonomous organizations.

Across the EU, obligations on public service providers have been imposed [12], such as security of supply and obligation to supply. The public takes reliable public services for granted. Apart from reliable, public services must be universal, i.e. all of the public should be equally entitled to benefit from it. Although some customers are more desirable than others, the obligation to supply demands that everyone has access to the service.

In advanced economies, however, what defines a public service is increasingly complex and blurred. In seeking to define the role of public services, it is worth remembering why they exist: to improve the quality of people's lives. However, this definition is too broad, and could include Tesco's supermarkets or Virgin Holidays. Some key characteristics set public services apart [28]:

- They rely upon an element of taxpayers' money to be provided.

- They accept an extended type of accountability, and are subject to a form of democratic scrutiny.

- They have a defined customer base. Most public services are unable to choose their customers, and most customers are unable to choose their public service supplier.

In a recent New Local Government Network (NLGN) commissioned survey [28], the public was asked what defines a public service. The two top definitions of public service were: "available for everybody to use" (40\%) and "important to the whole community" (38\%). Furthermore, 23\% of respondents believed that a key definition is the management of the service by central government, and only $4 \%$ thought that a public service had to be provided free at the point of use. This complies with other opinion surveys that have found that the role of the private sector in public services is a low salience issue. This may relate to the fact that profit is not a barrier to the delivery of effective public services.

Apart from the economic and political characteristics of public services, there are some functional characteristics that can be useful in our analysis. Public services tend to provide a stable, static product that does not change very often [22]. In fact, changes to public services need to go through the public's scrutiny.

This relative stability and coherence has some very important implications. The products and services persist over a long period of time, usually spanning more than one generation. As a result, they become embedded in the way of life of individuals, who then reinforce this way of life upon their children. Most children are told not to put their fingers in the electricity sockets, not to dial random numbers on the phone, to call 911 if an emergency occurs. In fact, they become so embedded in our lives that they tend to pervade the social and cognitive environments of people. This is well illustrated in emergency situations, when most people tend to be overwhelmed or stressed, yet are still able to use the phone service, or get access to electricity and water.

Offering a service as a public service, and submitting it to the general functional characteristics mentioned above, would result in a service that pervades the social and cognitive environments. People would use this service so many times, and 
would have enough experience with it, that they would be able to use it even in the most extreme situations. These characteristics are really attractive for a different category of services: pervasive services. In the following section we discuss how we can build pervasive systems in such as to benefit from these.

\section{Designing public pervasive systems}

So far, we have identified and addressed a number of important factors in the successful design and deployment of truly pervasive systems. We have discussed what social constructs should be taken into account during the design stage. Using these constructs, in this section we will provide guidelines for identifying which tasks should be supported by pervasive systems in public and private spaces. Additionally, we have described the social issues that underpin public spaces themselves. These issues enable us to describe how pervasive systems can be installed in public spaces, in such a way that they exist and operate in harmony with the existing social dynamics.

Finally, by discussing the characteristics of emergency situations, we have come to an understanding of what makes a service successful. If we manage to make pervasive systems useful in emergency situations, they are very likely to be successful in the majority of non-emergency situations. To make this happen, we discuss how pervasive systems could be provided as a public service.

\subsection{Deciding which services to offer}

How do we decide which services should be available in a specified location? Since we have classified tasks (and the digital services supporting them) into the notions of spheres, what we are really looking for is a way of assigning a particular sphere to a particular space. Intuitively, it seems that public spaces, because of their lack of privacy and safety, should be linked with the public sphere. Thus, services that "exist" in the public sphere should be made available in public spaces. For example, such services could be public broadcasts, public transportation information, discussion forums and so on.

Furthermore, since social spaces offer adequate safety and privacy, they could utilize services from the social sphere, and vice versa. For instance, services targeting interpersonal relationships, like chatting and video conferencing, would fall in this category. Such services would require a certain degree of privacy on behalf of all the users, but at the same time would allow others (most commonly specific individuals such as friends and relatives) to join in and be part of what is happening.

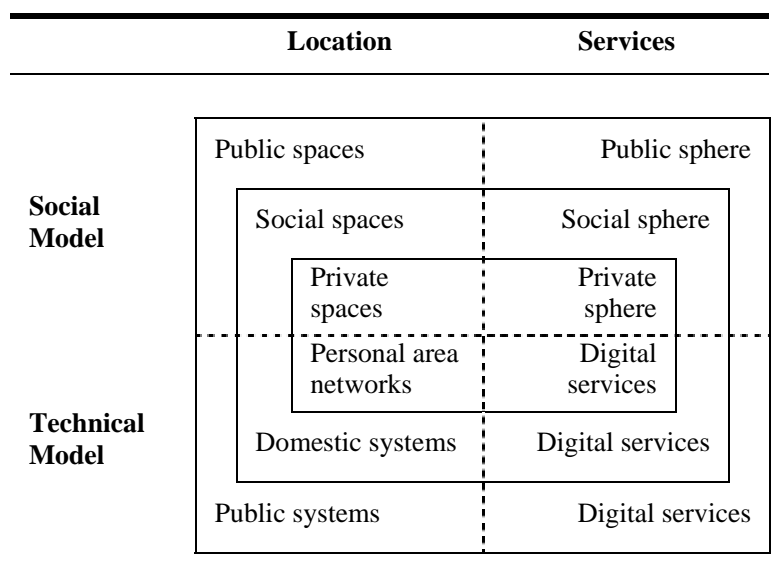

Figure 2. Mapping between location and

services, using our social and technical models.

Finally, services categorized in the private sphere should only be accessible to individuals directly associated with the information that is being accessed. For example, sensitive private information such as bank details should be accessible only by the owner of the bank account, and no one else (unless the owner specifies otherwise). What this also implies is that the presence of others within a public or even private space would have an impact on the accessibility of services of the private sphere.

This mapping of digital services to physical location is shown in Figure 2. Public, private, and personal spaces are mapped to digital services of the public, social, and private spheres respectively. However, this simplest mapping is rather too simple. It is beyond the scope of this paper to address all of the potential relationships amongst the elements in Figures 1 and 2. However, it is worth noting, for example, that a citizen might wish to perform a social sphere activity or task in a public space.

\subsection{Installing a public pervasive system}

As noted by the Project for Public Spaces [23], successful public spaces are accessible, they allow people to engage in activities, they are comfortable, and they are sociable. From these four key characteristics, follow a number of issues that should be considered in the design of public pervasive systems. In terms of allowing easy access, we should consider how the presence of the pervasive system is made "visible" or somehow manifested, so that people both in and outside the public space are aware of its existence. Moreover, people should enjoy easy access to the pervasive system, in terms of both connecting to it and using it. Of course, people with special needs should also be taken into account. Pervasive systems should also enhance and augment the comfort provided 
by the public space. This means that any sensory, e.g. visual or auditory, manifestation of the pervasive system should be appealing. In addition, a clearly represented, and in some cases manipulable, level of security should be provided by the public pervasive system, so that the users do not feel threatened or alienated by it. Finally, activities are the basic characteristics of a public space. A pervasive system should facilitate this and allow users to engage in activities, including group activities.

\subsection{Providing pervasive systems as public services}

So far, we have said that all users/citizens should have access to a public pervasive system. This means that a wide variety of people, including young and old, male and female, and people of various ethnicities should be able to use the system. This issue is being addressed by the notion of universal access [27] or universal usability [26]. The goal is to make computer systems accessible and usable by everyone, much like television, electricity and cars. It also has roots in the US Communications Act of 1934, which attempts to ensure that facilities are provided without "discrimination on the basis of race, color, religion, national origin, or sex" (section 1, 47 U.S.C. 151). Furthermore, universal access would allow government-based electronic facilities to be used by the public, at its most simple level including, for example, electronic voting.

Apart from the user interaction issues that universal usability addresses, other issues are raised by the citizenship rights described in section 4.1. These imply that people require adequate and unbiased information circulating in the public sphere in order to make informed decisions and to take part in the everyday democratic process. This is recognized by legislation and has resulted in the perception that access to information is a public good [8].

A public pervasive system with adequate area coverage could be regarded as a nationwide carrier of information which is accessible by the public. By definition, a nationwide carrier of a public good is seen as a public service. This perception in itself can have great consequences for the way in which the system is used, what people expect from it, and indeed what people demand of it. Other public services, such as the telephone, tend to pervade the social and cognitive environments as a result of people using them repetitively and from a very young age. A pervasive system that is offered and perceived as a public service could reach its full potential by pervading the physical, social, and cognitive environments to a similar extent.
The importance of the relationship between citizenship and public services has been recognized and very well supported by the UK government. The Citizen's Charter, launched in 1991, was a means of improving aspects of public service delivery. The charter was relaunched and refocused by the Government as Service First in June 1998 [4]. Under this initiative, nine principles of public service delivery were published, based on existing charter principles. These principles include setting standards of service, treating all fairly, consulting and involving, and using resources efficiently. This initiative is a very positive indication of the importance that governments attach to public services, the potential requirements of providing pervasive systems as public services, and the potential benefits of doing so.

But in order for pervasive systems to benefit from an increased use and familiarity that other public services enjoy, care must be taken that the existing paradigms of conventional public services are followed as closely as possible. Any attempt to provide a service to large numbers of people is bound to run into problems if the users are expected actively to contribute to the continued operation of the system, or any part of it. This would result in users feeling that they are actually contributing more than they get in return. When using a publicly available resource, we expect to be treated in the same way as everyone else, not better or worse. Furthermore, we expect the service to be reliable and not dependent upon us for its operation. This can be seen in public transportation (buses, trains etc) and public services in general (hospitals, police, fire brigade, etc).

A close inspection of successful public services reveals a number of common characteristics. For instance, the expectation of receiving the same service regardless of physical location or who is using it. This does not imply that the service cannot be personalized; indeed personalization plays a key role in user satisfaction. Instead, what the users expect is that personalization is available to others as well.

As a result of the expectations for uniformity and consistency we see a somewhat centralized structure when it comes to delivering such services. This has resulted in the development of notions and ideas that are applied to new forms of services, as they come along. Good examples are the notions of a "station", a "centre”, or a "provider". Furthermore, not one of the above services actively relies on its users for its day to day operation. Users may enjoy the services without much work. It seems that we prefer the stability and consistency of a centralized service provider instead of a flexible decentralized system in which the user has increased responsibilities. This could be the case for pervasive systems as well. 
Maintaining the required stability and uniformity for a service can best be achieved with a centralized way of providing the service. Also, the users should be treated uniformly, regardless of physical point of access, real identity of user, social status of the user, etc. Furthermore, the services need to be simple enough to be used by anyone, regardless of their age, education, gender and race. Also, dedicated and specialized personnel should be available for repairing damages and faults to the system, much like the telephone repair personnel who are responsible for fixing problems with the phone network.

Of course, it is clear that in terms of technology, implementation and design, pervasive systems are nothing like e.g. the bus service, both from the provider and the user perspective. However, we have identified a number of common characteristics that are found in almost every successful public service. Therefore, we could try to incorporate such characteristics in our pervasive system designs, or at least provide design characteristics that cause users to perceive the new technology as yet another form of publicly available service.

\section{Conclusion}

The work we have reported here addresses social issues in the provision of public pervasive computing systems. We began with an account of how pervasive systems, in their current form, are constrained both physically and conceptually. We then described our approach to designing pervasive systems that attempts to overcome these constraints.

We drew a fundamental distinction between public and domestic pervasive systems. With this distinction in mind, we surveyed current systems and identified technologies and methods that could be applied to public pervasive systems. Drawing on the established HCI design foci of user, task and domain, we arrived at our model of Citizen - Sphere - Space. This model has offered us important insights.

First, we have proposed a means of mapping digital services to physical locations by establishing the relationships amongst public, private and social spheres and spaces. A second insight suggested how pervasive systems could be integrated in our physical environment. We proposed guidelines for making a pervasive system successful, based on the requirements for successful public spaces. Finally, we provided a model for how digital pervasive services could be offered. This model, which follows from citizenship rights, is based on the public services paradigm and as such, carries with it a number of consequences for our designs.
Our next goal is to further develop our conceptual work, especially in refining the public services model for pervasive computing. Our current work is aimed at identifying the implications of providing digital pervasive services as public services, as well as offering a more concrete and specific description of how this could be implemented.

The guidelines that we have developed for integrating pervasive systems in public spaces are specific enough to allow for the implementation of a prototype system, which we are currently developing. The technology, or at least the political and commercial will to apply it, is not quite yet available for the implementation of a large-scale public pervasive system in the way we envision it. Nevertheless, the technology is evolving much more quickly than society. For successful pervasive systems, we need to work now to have a better understanding of the social and design issues before the technology arrives to turn them into social and design opportunities or problems.

\section{Acknowledgments}

Many thanks to Emma Carmel and Theo Papadopoulos for their valuable input and contribution. We also thank our colleagues at the University of Bath Human-Computer Interaction Group, especially Hilary Johnson and Rachid Hourizi, for their insightful comments and ideas. Finally, we are grateful for the comments and suggestions that the reviewers have provided.

\section{References}

[1] Bederson, B.B., Lee, B., Sherman, R.M., Herrnson, P.S., and Niemi, R.G., "Electronic voting system usability issues", in Proceedings of the SIGCHI 2003 Conference on Human factors in computing systems, Florida, USA, pp.145152, 2003.

[2] Borovoy, R., Martin, F., Resnick, M., and Silverman, B., "GroupWear: Nametags that Tell about Relationships", in CHI 1998 Conference summary on Human factors in computing systems, California, USA, pp.329-330, 1998.

[3] Brumitt, B. and Shafer, S., "Better living through geometry”, Personal and ubiquitous computing, 5(1), pp.4245, 2001.

[4] Cabinet Office, Service First: The new charter programme, London, Cabinet Office, 1998.

[5] Dey, A., Abowd, G., and Salber, D., “A conceptual framework and a toolkit for supporting the rapid prototyping of context-aware applications”, Human-Computer Interaction, 16, pp.97-166, 2001.

[6] Esler, M., Hightower, J., Anderson, T., and Borriello, G., "Next Century Challenges: Data-Centric Networking for Invisible Computing", in Proceedings of the Fifth Annual 
ACM/IEEE International Conference on Mobile Computing and Networking, Washington, USA, pp.256-262, 1999.

[7] Fraser, N., "Politics, culture and the public sphere: towards a postmodern conception", in Social Postmodernism: Beyond Identity Politics, L. NICHOLSON AND S. SEIDMAN, Eds. Cambridge University Press, Cambridge, 1995.

[8] Green, L. Communication, Technology and Society, Sage Publications, 2001.

[9] Grosz, B,J., and Kraus, S., "Collaborative plans for complex group action”, Artificial Intelligence, 86(2), pp.269357, 1996.

[10] Habermas, J., Strukturwandel der Offentlichkeit, Neuwied Berlin, Luchterhand, 1962; 2nd edn, Frankfurt, Suhrkamp, 1989. Translated as The structural transformation of the public sphere, Cambridge, Polity, 1989.

[11] Harrison, H. and Dourish, P., "Re-place-ing space: the roles of place and space in collaborative systems", in Proceedings of the 1996 ACM conference on Computer Supported Cooperative Work, Massachusetts, USA, pp.6776, 1996.

[12] Harrison, J., and Woods, L.M., "Defining European Public Service Broadcasting”, The European Journal of Communication, 16(4), pp.477-504, 2001.

[13] Hightower, J. and Borriello, G., "Location systems for ubiquitous computing”, IEEE Computer, 34(8), pp.57-66, 2002.

[14] Ishii, H. and Ullmer, B., "Tangible bits: towards seamless interfaces between people, bits and atoms”, in Proceedings of the SIGCHI Conference on Human factors in computing systems, Georgia, USA, pp.234-241, 1997.

[15] Johnson, H. and Johnson, P., “Task Knowledge Structures: psychological basis and integration into system design”, Acta Psychologica, 78, pp.3-26, 1991.

[16] Jolly, E.J., and Reardon, R., "Cognitive differentiation, automaticity, and interruptions of automatized behaviours", Personality and Social Psychology Bulletin, 11(3), pp.301314, 1985.

[17] Kindberg, T., Barton, J., Morgan, J., Becker, G., Caswell, D., Debaty, P., Gopal, G.,Frid, M., Krishnan, V., Morris, H., Schettino, J., Serra, B., and Spasojevic, M., "People, places, things: web presence for the real world", Mobile Networks and Applications, 7(5), pp.365-376, 2002.

[18] Kostakos, V. and O'Neill, E., “A Directional Stroke Recognition Technique for Mobile Interaction in a Pervasive Computing World”, People and Computers XVII, Proceedings of HCI 2003: Designing for Society, Bath, UK, pp.197-206, 2003.

[19] Krajewski, M., "Public Services and the Scope of the General Agreement on Trade in Services”, Center for
International Environmental Law Research Paper, Geneva, May 2001.

[20] Lyytinen, K. and Yoo, Y., "Issues and challenges in ubiquitous computing”, Communications of ACM, 45(12), pp.63-65, 2002.

[21] Marshall, T.H., Citizenship and social class, Cambridge at the University Press, 1950.

[22] Patterson, W., "Transforming electricity: the coming generation of change", Royal Institute of International Affairs / Earthscan, New Series, 4, 1999.

[23] Project For Public Spaces, How to turn a place around, Project for Public Spaces Inc., December 2000. For more information see http://www.pps.org

[24] Rekimoto, J., "GestureWrist and GesturePad: Unobtrusive Wearable Interaction Devices", in the Fifth International Symposium on Wearable Computers, pp.21-30, 2001.

[25] Rodden, T., and Benford, S., "The evolution of buildings and implications for the design of ubiquitous domestic environments", in Proceedings of the SIGCHI 2003 Conference on Human factors in computing systems, Florida, USA, pp.9-16, 2003.

[26] Shneiderman, B., Leonardo's laptop. Human needs and the new computing technologies, The MIT Press, Cambridge, Massachusetts, 2002.

[27] Stephanidis, C., “Adaptive Techniques for Universal Access", User Modelling and User-Adapted Interaction, 11(1-2), pp.159-179, 2001.

[28] Stoker, J. and Williams, J., "Memorandum by Professor Gerry Stoker, Chair and John Williams, Executive Director, New Local Government Network (PSR 11)", Select Committee on Public Administration, Minutes of Evidence, 29 Nov. 2001, The United Kingdom Parliament.

[29] Sullivan, D.G., Glass, A., Grosz, B, J., and Kraus, S., "Intention reconciliation in the context of teamwork: An initial empirical investigation", in KLUSCH. M. et al Cooperative Information Agents III, Lecture Notes in AI, 1652, Springer-Verlag, pp.149-162, 1999.

[30] Tunstall, R., "Devolution and User Participation in Public Services: How They Work and What They Do", Urban Studies, 38(13), pp.2495-2514, 2001.

[31] Vanhala, J., "A flood of Intelligence - the Living Room Project”, ERCIM News, 47, pp.14-15, 2001.

[32] Want, R. Hopper, A., Falcao, V., and Gibbons, J., “The Active Badge locator system", ACM Transactions on Information Systems, 10(1), pp.91-102, 1992.

[33] Weiser, M., "The Computer for the Twenty-First Century”, Scientific American, 265(3), pp.94-104, 1991. 